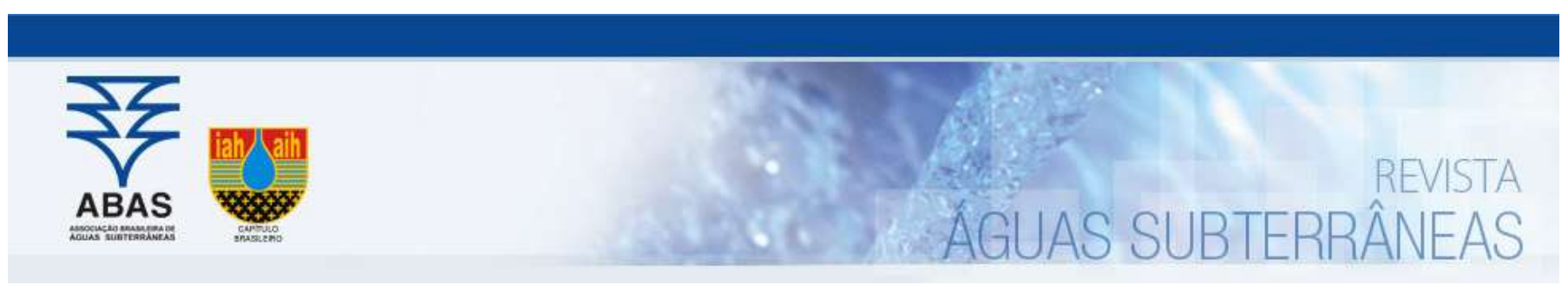

Estudos de Caso e Notas Técnicas

\title{
Contribuição ao conhecimento da hidráulica subterrânea do aquífero Jandaíra na região de Baraúna - RN
}

\author{
Contribution to knowledge of groundwater hydrology of the Jandaíra aquifer in the \\ region of Baraúna - RN
}

\author{
José Geilson Alves Demétrio ${ }^{1}$; Ana Gabriella dos Santos Batista 1 ; José Geraldo de Melo1 ${ }^{\bowtie}$ \\ 1 Universidade Federal de Pernambuco (UFPE), Recife, PE \\ 2 Universidade Federal do Rio Grande do Norte (UFRN), Nata, RN
}

$\bowtie$ geilsonad@yahoo.com.br, anaghaby20@hotmail.com,jgmelo2@gmail.com

\section{Resumo}

Palavras-chave:

Aquífero Jandaíra.

Barauna.

Mizu.

Chapada do Apodi.

Aquífero cárstico

\begin{abstract}
O aquífero Jandaíra, que ocorre na área da chapada do Apodi, entre os Estados do Rio Grande do Norte e Ceará, onde está inserida a área de estudo, é uma importante fonte de água para a irrigação de extensas áreas de fruticultura. Devido a sua natureza cárstica, a hidrogeologia é naturalmente bastante complexa. A compreensão da hidráulica desses aquíferos é de fundamental importância propiciar uma gestão mais efetiva, visando a sua preservação. Nesse sentido foram desenvolvidos estudos geológicos, geofísicos e hidrogeológicos, que mostraram que a carstificação diminui com a profundidade. Na área estudada a carstificação atinge até cerca de 30 metrosde profundidade. 0 trabalho também mostrou que a posição do nível d'água varia de acordo com o regime das chuvas. Nas épocas de grandes secas, como a última que durou seis anos, os níveis aprofundaram bastante e a maioria dos poços diminuíram a produtividade, ao ponto de não ser possível usá-los para irrigação, uma vez que as vazões desses poços dependem da rede de carstificação superficial.
\end{abstract}

Abstract

Keywords:

Jandaíra Aquifer.

Barauna.

Mizu.

Apodi plated.

Karst aquifer.

Revisado por pares.

Recebido em: 26/12/2017.

Aprovado em: 24/01/2018

\begin{abstract}
The Jandaíra aquifer, which occurs in the Apodi Plateau area, between the States of Rio Grande do Norte and Ceará, where the study area is located, is an important source of water for the irrigation of extensive fruit growing areas in the Baráuna region, RN. Due to its karst nature, hydrogeology is naturally quite complex. The knowledge of groundwater hydrology is fundamental for understanding the hydraulics of these aquifers. Which may lead to a more effective management, aiming at its preservation. In this sense, geological, geophysical and hydrogeological studies were developed, which showed that karstification decreases with depth. In the studied area the karsification reached up to about 30 meters. The work also showed that the position of the water level varies according to the rainfall regime.In times of great droughts, such as the last six years, the levels deepen greatly and most of the wells have reduced productivity, to the point that it is not possible to use them for irrigation, since the yield of these wells depend on the network of superficial karstification.
\end{abstract}

DOI: http://dx.doi.org/10.14295/ras.v32i1.29083

\section{INTRODUÇÃO}

A região no entorno da cidade de Baraúna, no Rio Grande do Norte, destaca-se há anos pela fruticultura irrigada, sendo reconhecida como um grande polo de abastecimento para várias cidades e capitais brasileiras, além de mercados no exterior. A fonte hídrica da irrigação é a água subterrânea do aquífero Jandaíra, formado por rochas carbonáticas da formação homônima.

Pela sua natureza calcária, o aquífero é do tipo fraturado. A dissolução da rocha pela ação das águas das chuvas promove a abertura das fraturas, chegando a transformarem-se em caver- nas, que conseguem acumular grandes volumes de água.

Há décadas que se vem promovendo, com relativa intensidade, a irrigação na região de Baraúna a partir do aquífero Jandaíra, o que torna fundamental a adoção de medidas de gestão dos recursos disponíveis. No início da década de 2000 os níveis da água do aquífero chegaram a profundidades críticas, inviabilizando a irrigação em diversas propriedades (FEITOSA, 2003, p. 8).

Atualmente a região vem passando por uma severa seca, que já dura cinco anos, com aprofundamentos dos níveis de água mais 
intensos do que os registrados no início dos anos 2000. Na figura 01, é apresentado o hietograma do posto da Emater em Baraúna. Estão disponíveis na internet (http://www.emparn.rn.gov.br/) dados de 1960 até os dias de hoje, porém, com uma lacuna entre 1990 e 2002, assim, no gráfico só são apresentadas as chuvas de 2003 até abril de 2017. Como se pode perceber na figura 01, os últimos cinco anos foram classificados, segundo a classificação da Emparn, como muito secos e secos.

Figura 01 - Precipitações anuais em Baraúna entre 2003 e 2017

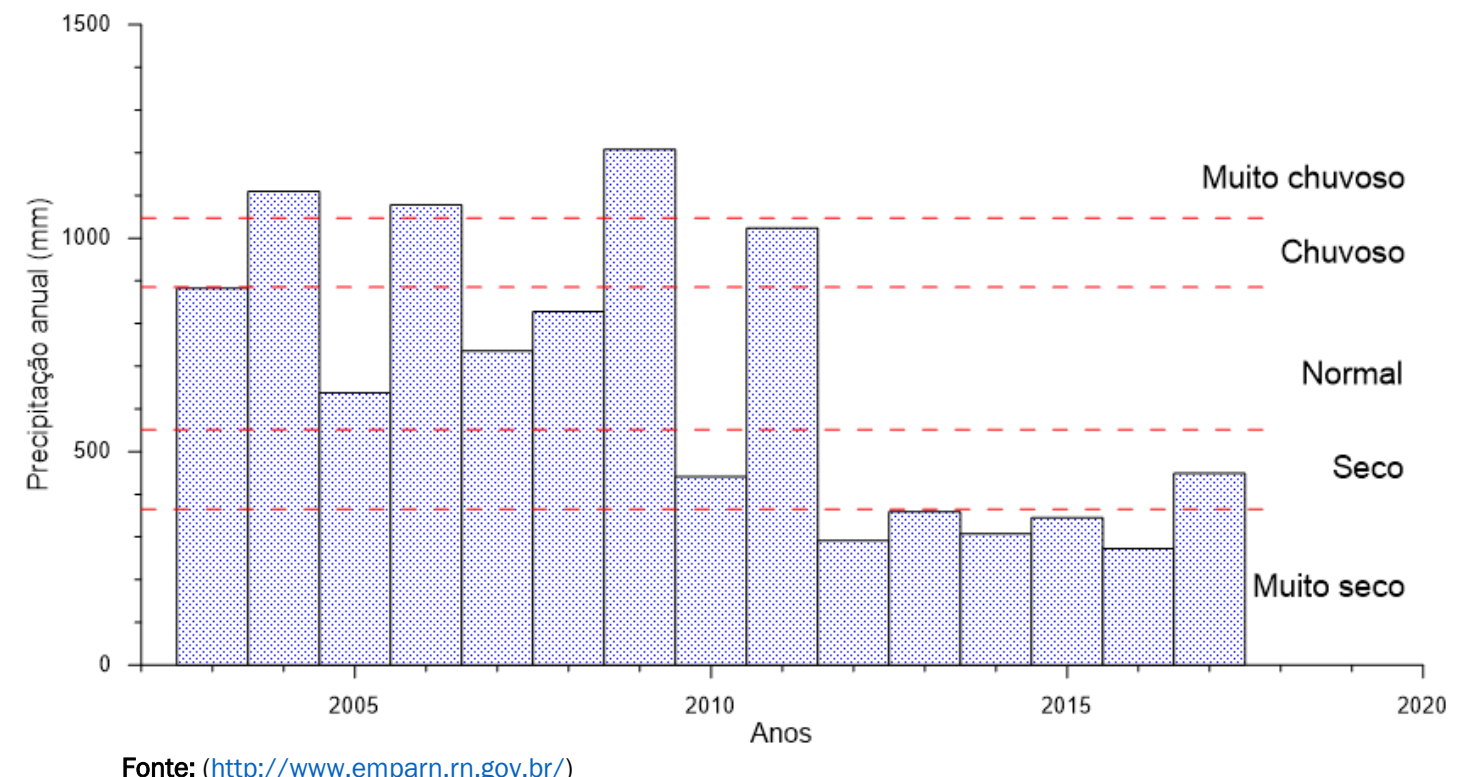

Alguns poços, que antes produziam até $50 \mathrm{~m}^{3} / \mathrm{h}$ no período chuvoso, secaram, ficando a irrigação restrita às propriedades cujos poços atingiram zonas fraturadas diferenciadas ou com maior carstificação. Esses, continuaram produzindo água mesmo no período seco (FUNPEC/MIZU, 2013, p 71). Apesar dessas variações acentuadas do nível da água do aquífero, foi verificado, com base em mais de dez anos de monitoramento de poços captando o aquífero Jandaíra, no entorno da cidade de Baraúna, que o bombeamento dos poços tem pouca influência no nível d’água, tendo essas variações sido atribuídas ao regime pluviométrico (DEMETRIO et al., 2016, p. 264).

Em um aquífero tão complexo, como o cárstico, é fundamental a compreensão do seu comportamento hidráulico para que se possa fazer uma gestão adequada dos seus recursos hídricos.

\section{LOCALIZAÇÃO}

A área de estudo está situada na chapada do Apodi, entre os municípios de Baraúna-RN e Quixeré-CE. Na figura 02 é mostrada a localização e situação da área de trabalho.

\section{CONTEXTO GEOLÓGICO}

A Bacia Potiguar localiza-se na região nordeste do Brasil, esten- de-se pelos estados do Rio Grande do Norte e do Ceará. Geologicamente, limita-se a leste com a Bacia Paraíba, pelo Alto de Touros, a noroeste com a Bacia do Ceará pelo Alto de Fortaleza e ao sul com rochas do embasamento cristalino. Geotectonicamente está inserida no domínio setentrional da Província Borborema (ANGELIM, 2007, p.37).

Araripe e Feijó (1994 p130) dividiram a bacia potiguar em três unidades litoestratigráficas: grupo Areia Branca, Apodi e Agulha. A formação Jandaíra está no grupo Apodi, que é de idade albaniana a campaniana, constituem uma sequência transgressiva que se inicia com sedimentos continentais clásticos, principalmente arenitos e pelitos, Formação Açu, que gradam para sedimentos de plataforma rasa e carbonatos. A sequência termina com os folhelhos e carbonatos da formação Jandaíra, que afloram na bacia Potiguar.

$\mathrm{Na}$ área estudada afloram apenas calcários da formação Jandaíra, de coloração cinza e creme. Intensamente carstificados, sendo comum na área a existência de sumidouros. Foram encontrados, principalmente na área de lavra da mina do Cimento Mizu, intercalações de arenitos, folhelhos, margas e evaporitos, (MIRANDA et al., 2012, p.17). 


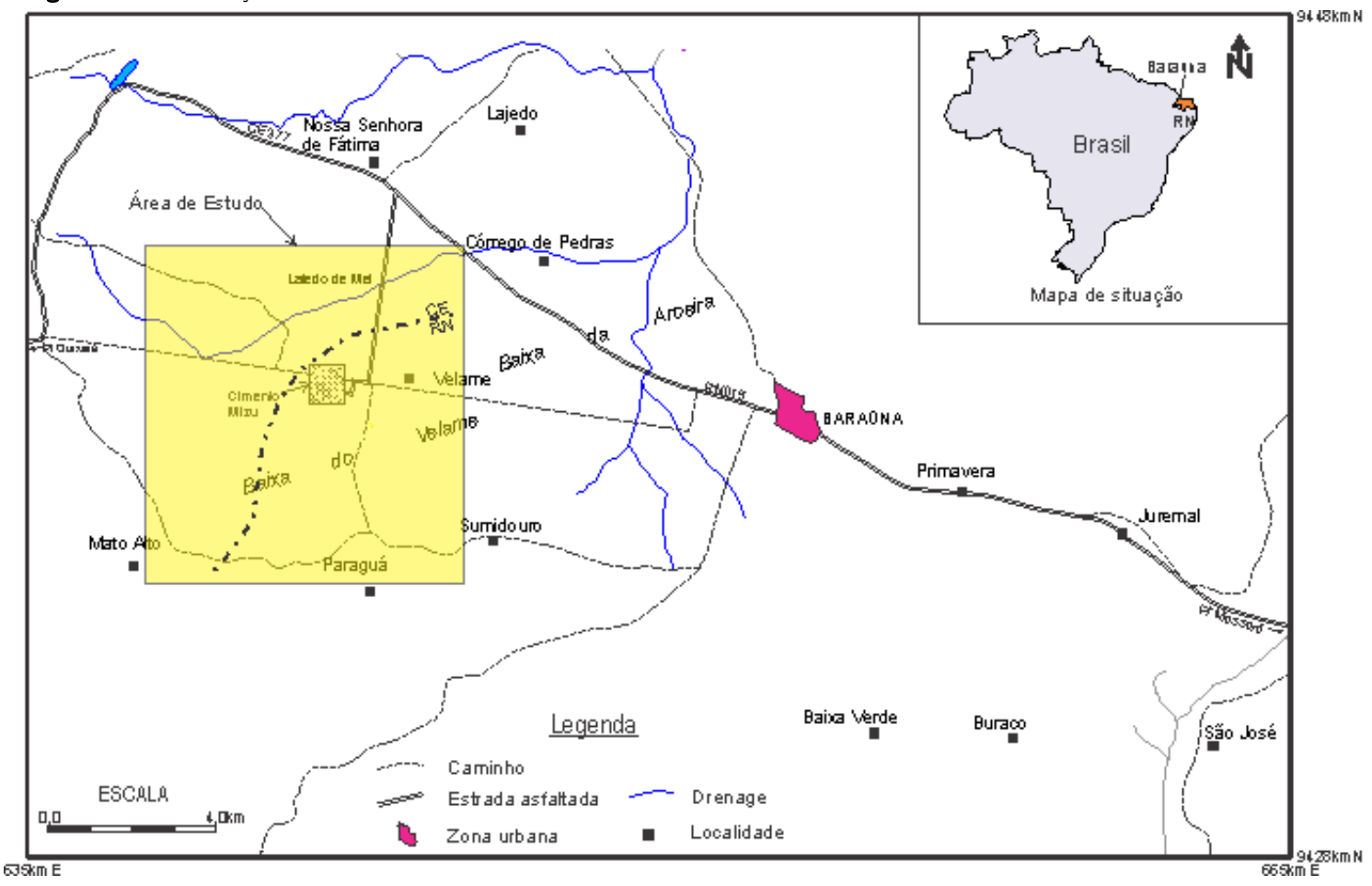

\section{CONTEXTO HIDROGEOLÓGICO}

Para a caracterização hidrogeológica do aquífero Jandaíra foi feito um inventário dos poços na área estudada, com visita à 156 poços, dos quais 20 foram selecionados para comporem a rede de monitoramento de níveis e qualidade da água. Para completar a rede de monitoramento foram ainda construídos 16 poços tubulares, para comporem a rede de monitoramento e estudos complementares, dos quais cinco foram utilizados para a realização de ensaios de bombeamento, tendo em vista a avaliação de parâmetros hidrogeológicos do aquífero

O aquífero Jandaíra é do tipo cárstico-fissural livre, (MANOEL FILHO et al., 2003 p. 25), sem qualquer relação hidráulica com o aquífero Açu sotoposto. As espessuras do calcário Jandaíra na área de estudo são da ordem de 300,0 metros, (ANA, 2010, p.87).

Como na área só afloram rochas calcárias, a ênfase dos mapeamentos foi voltada para a detecção de fraturas (FUNPEC/MIZU, 2013, p.140), por serem os elementos controladores da hidrogeologia dos aquíferos cársticos. No mapa de figura 03, é apresentado o padrão de fraturamento encontrado.

\subsection{Avaliação do comportamento hidráulico}

Para a caracterização do comportamento hidráulico do aquífero Jandaíra, na área da Mizu, foi planejada inicialmente a construção de três dispositivos (poço de bombeamento mais poços de observação) para a realização de ensaios de bombeamento. Porém, já na fase de perfuração desses poços se percebeu que os mesmos seriam de baixa produtividade. Assim, além desses três conjuntos de poços, foram construídos mais dois poços produtores para complementar os estudos.
A locação dos cinco poços de bombeamento foi feita com base nas informações de poços existentes nas vizinhanças da Mizu e dos estudos geológicos realizados no âmbito do projeto. Como se trata de um meio fraturado a locação dos poços basicamente buscou identificar zonas mais intensamente fraturadas. Os poços de bombeamento foram denominados de $\mathrm{Pb}-01, \mathrm{~Pb}-02, \mathrm{~Pb}-$ 03, $\mathrm{Pb}-04$ e Pb-05, mostrados no mapa da figura 03. Todos os poços ficaram com 80,0 metros de profundidade, revestidos apenas os primeiros $8,0 \mathrm{~m}$, trecho mais susceptível ao desmoronamento, utilizando tubo de PVC geomecânico de 6,0 polegadas de diâmetro. Os poços de observação, construídos entre 20,0 e 30,0 metros dos poços de bombeamento, foram perfurados em 8,0 polegadas até 30,0 metros de profundidade, revestidos com tubos e filtros geomecânicos de 4,0 polegadas e o espaço anelar preenchido por cascalho quartzoso de $8,0 \mathrm{~m}$ de profundidade até o fundo do poço. Acima dos 8,0 metros o espaço anelar foi preenchido por uma pasta de cimento e água.

Além dos poços construídos especificamente para as finalidades do projeto, também foram utilizadas, como poço de observação, algumas das sondagens realizadas para a cubagem da jazida de calcário.

\subsection{Ensaios de bombeamento preliminares - Pré-teste}

Após a construção dos poços foi feito um pré-teste, para se avaliar preliminarmente as capacidades de produção dos cinco poços. Na tabela 1 são apresentados os dados coletados no poço $\mathrm{Pb}-03$, por ter sido o mais longo, com informação de bombeamento e recuperação. A bomba foi instalada, em todos os poços, aos sessenta metros de profundidade. Em todos, o nível dinâmico chegou ao nível da bomba, ou muito próximo a esta. 
Figura 03 - Padrão do fraturamento do aquífero Jandaíra na área estudada

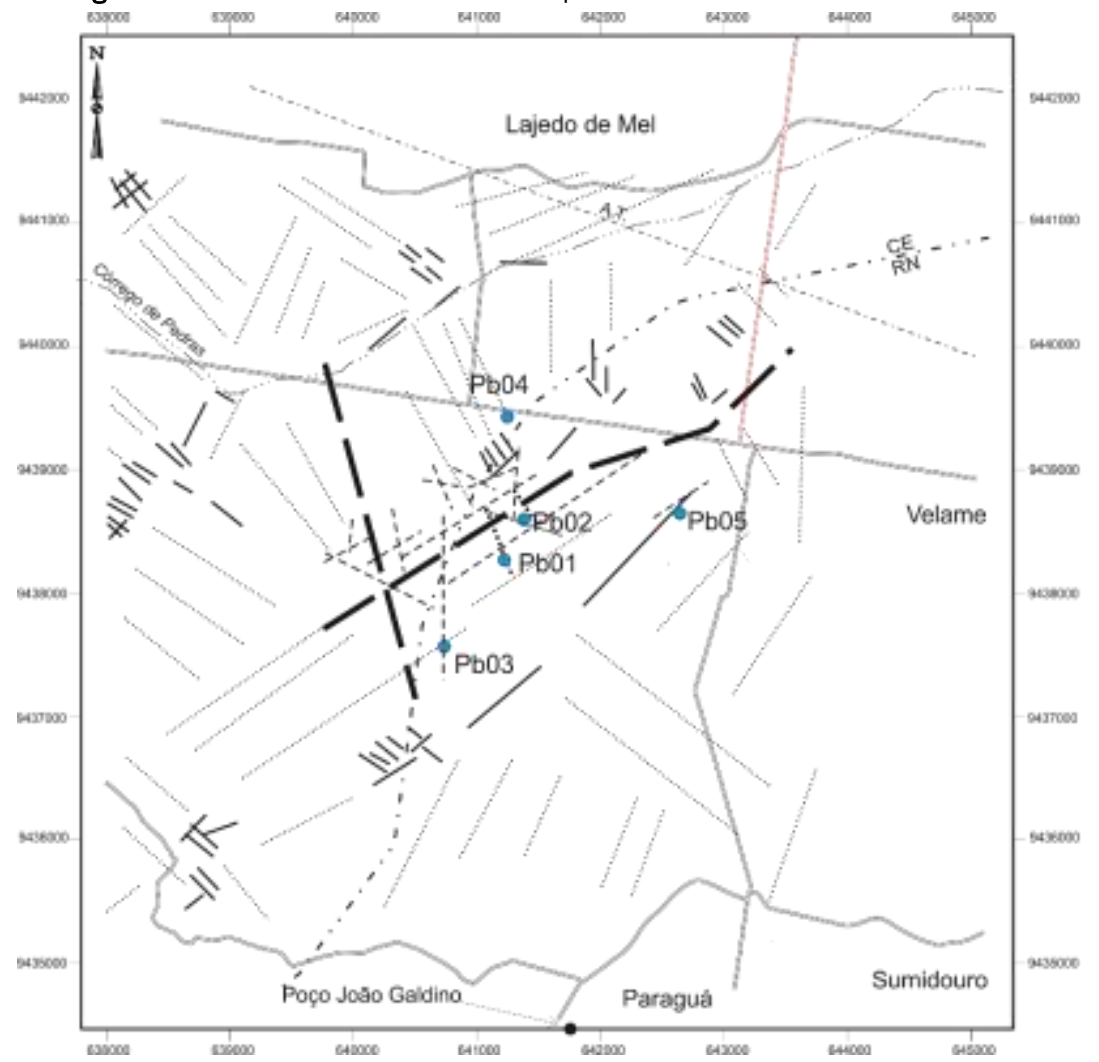

\section{Legenda}

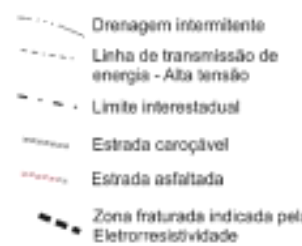

- Pocos de pesquisa para

? Fraturss imbenidas a pert de imagens Google

Frabiras mapeameadas no escudo

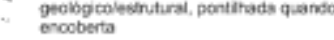

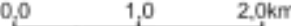

Tabela 1 - Pré-teste do Pb-03

\begin{tabular}{ccccc}
\hline $\begin{array}{c}\text { Tempo } \\
(\mathrm{min})\end{array}$ & $\begin{array}{c}\text { ND } \\
(\mathrm{m})\end{array}$ & $\begin{array}{c}\text { ND' } \\
(\mathrm{m})\end{array}$ & $\begin{array}{c}\text { sw } \\
(\mathrm{m})\end{array}$ & $\begin{array}{c}\text { sw' } \\
(\mathrm{m})\end{array}$ \\
\hline 1 & 20,67 & 59,39 & 2,77 & 41,49 \\
2 & 22,68 & 58,82 & 4,78 & 40,92 \\
3 & 24,96 & 58,59 & 7,06 & 40,69 \\
4 & 27,18 & 58,63 & 9,28 & 40,73 \\
6 & 31,47 & 58,58 & 13,57 & 40,68 \\
9 & 38,10 & 58,58 & 20,20 & 40,68 \\
10 & 39,98 & - & 22,08 & \\
12 & 43,78 & - & 25,88 & \\
14 & 48,93 & - & 31,03 & \\
16 & 51,50 & - & 33,60 & \\
18 & 54,44 & - & 36,54 & \\
20 & 57,93 & - & 40,03 & \\
21,43 & 60,00 & - & 42,10 & \\
\hline
\end{tabular}

Obs.:NE=17,90; Vazão: 3,6m³/h; Data:25/07/14; ND': nível dinâmico recuperação; sw': rebaixamento recuperação

Nos gráficos da figura 04 são apresentadas as respectivas curvas rebaixamento $x$ tempo dos cinco pré-testes. Excetuando-se a curva do poço $\mathrm{Pb}-02$, cujo bombeamento não foi feito com vazão constante, os pontos ajustam-se perfeitamente a uma reta, chegando-se a um coeficiente de correlação igual a 1,0, no poço $\mathrm{Pb}-$ 04. É importante ressalta que os gráficos foram todos construídos com os eixos na escala linear, assim, os resultados de todos os pré-testes indicam que os poços foram bombeados como se fossem um cilindro fechado, sem contribuição de água do aquífero, ou uma contribuição insignificante. Em todos os bombeamentos os níveis dinâmicos atingiram a bomba em poucos minutos, variando apenas em função da vazão utilizada. Todas essas informações levam a concluir que o aquífero Jandaíra no local dos poços tem uma produtividade baixíssima.
Para demonstrar que os poços se comportaram como cilindro fechado foi feita uma simulação de um bombeamento, que na figura 04 foi denominado de simulação teórica. Nesta foi idealizado um reservatório cilíndrico com dez polegadas de diâmetro, com quarenta metros de coluna de água e uma vazão constante de bombeamento de $3,0 \mathrm{~m}^{3} / \mathrm{h}$.

Na tabela 2 é apresentado o resultado dessa simulação, na qual são apresentados os volumes bombeados para diferentes tempos de bombeamento e o rebaixamento correspondente.

O gráfico da simulação teórica, como se percebe na figura 04, é idêntico aos obtidos nos pré-testes, variando apenas os valores de rebaixamento por conta das diferentes vazões utilizadas. 
Figura 04 - Curvas rebaixamento $x$ tempo dos pré-testes
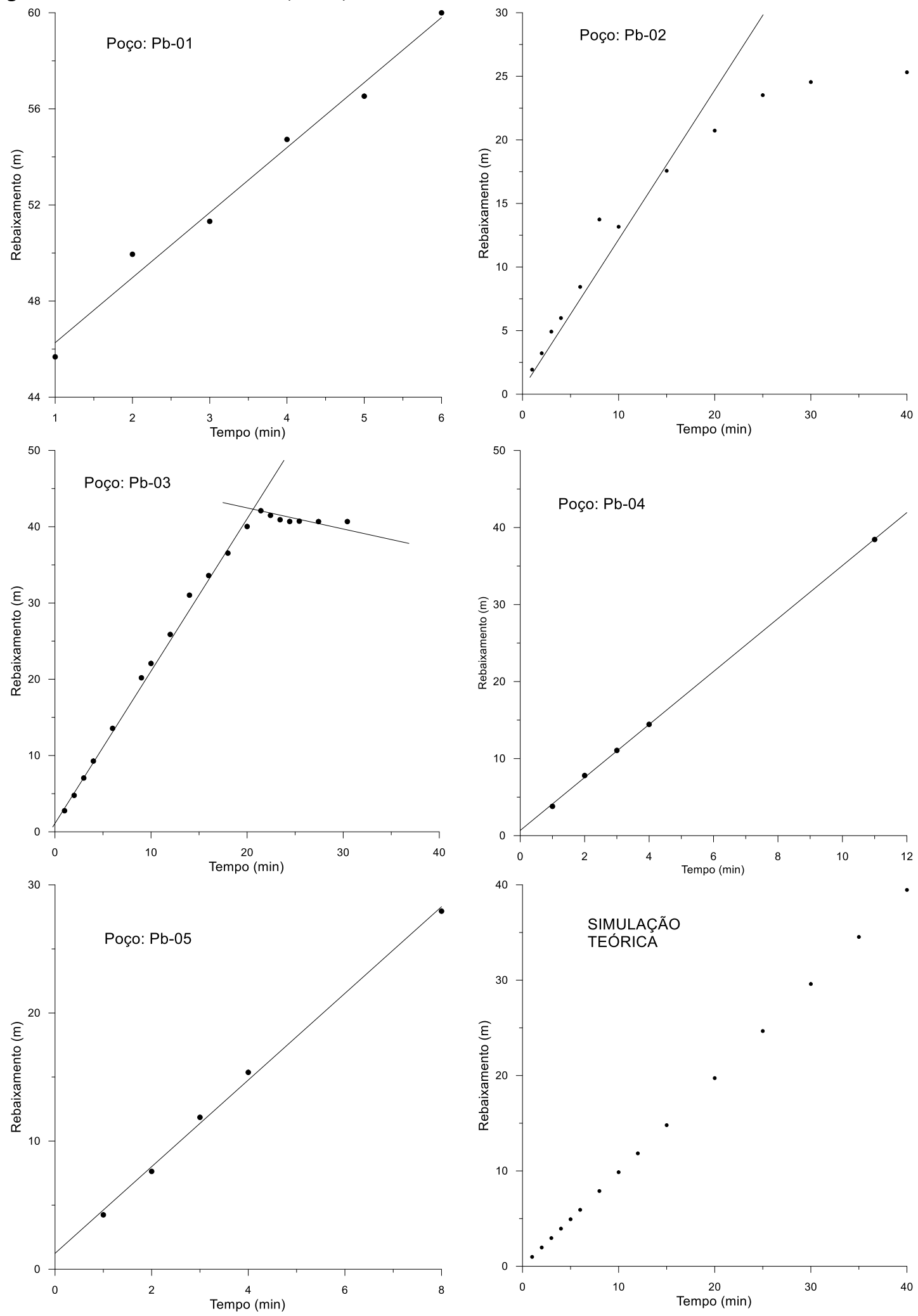

DEMÉTRIO, J.G.A. ; BATISTA, A. G.S. ; MELO, J.G.. Águas Subterrâneas, v. 32, n. 1, p. 52-60, 2018.56 
Tabela 2 - Resultados da simulação teórica

\begin{tabular}{rrrrrr}
\hline $\begin{array}{c}\text { Tempo } \\
(\mathrm{min})\end{array}$ & $\begin{array}{c}\text { V } \\
\left(\mathrm{m}^{3}\right)\end{array}$ & $\begin{array}{c}\text { sw } \\
(\mathrm{m})\end{array}$ & $\begin{array}{c}\text { Tempo } \\
(\mathrm{min})\end{array}$ & $\begin{array}{c}\mathbf{V} \\
\left(\mathrm{m}^{3}\right)\end{array}$ & $\begin{array}{c}\text { sw } \\
(\mathrm{m})\end{array}$ \\
\hline 1 & 0,05 & 0,99 & 12 & 0,60 & 11,84 \\
2 & 0,10 & 1,97 & 15 & 0,75 & 14,80 \\
3 & 0,15 & 2,96 & 20 & 1,00 & 19,74 \\
4 & 0,20 & 3,95 & 25 & 1,25 & 24,67 \\
5 & 0,25 & 4,93 & 30 & 1,50 & 29,60 \\
6 & 0,30 & 5,92 & 35 & 1,75 & 34,54 \\
8 & 0,40 & 7,89 & 40 & 2,00 & 39,47 \\
10 & 0,50 & 9,87 & & & \\
\hline
\end{tabular}

Durante os pré-testes os poços de observação, próximos aos poços bombeados, foram monitorados e nenhum deles esboçou qualquer variação do nível da água, além daquelas causadas pela oscilação da pressão atmosférica ao longo do dia, o que é mais um indicativo da baixa produtividade do aquífero.

Os pré-testes mostraram que os poços/aquífero são de baixíssima produtividade, mas não foram suficientes para definir que baixa produção seria essa. Para tanto, foi planejado um ensaio de bombeamento no $\mathrm{Pb}-03$, utilizando a menor vazão possível e uma observação longa da recuperação. Como a suspeita seria que no bombeamento não se conseguiria qualquer informação sobre a produção do aquífero, esperava-se que a recuperação fornecesse esse dado.

\subsection{Ensaio de bombeamento do poço $\mathrm{Pb}-03$}

O ensaio de bombeamento do poço $\mathrm{Pb}-03$ foi realizado em outubro de 2014, com quarenta e quatro horas de duração, sendo monitorado os poços de observação Pz-03, a vinte e cinco metros, e FDM-43, a 30 metros. A vazão foi mantida constante em 569,0 L/h com auxílio de um medidor de vazão ultrassônico Sitelab, modelo SL1188P. Nos poços de bombeamento e de observação foram instalados registradores automáticos de nível de água Schlumberger Diver, que foram programados para gravar as informações a cada minuto, porém, na figura 05 os dados do rebaixamento são apresentados para intervalos de dez minutos na fase de bombeamento e na recuperação intervalos de cinquenta minutos.

Figura 05 - Ensaio de bombeamento do poço $\mathrm{Pb}-03$

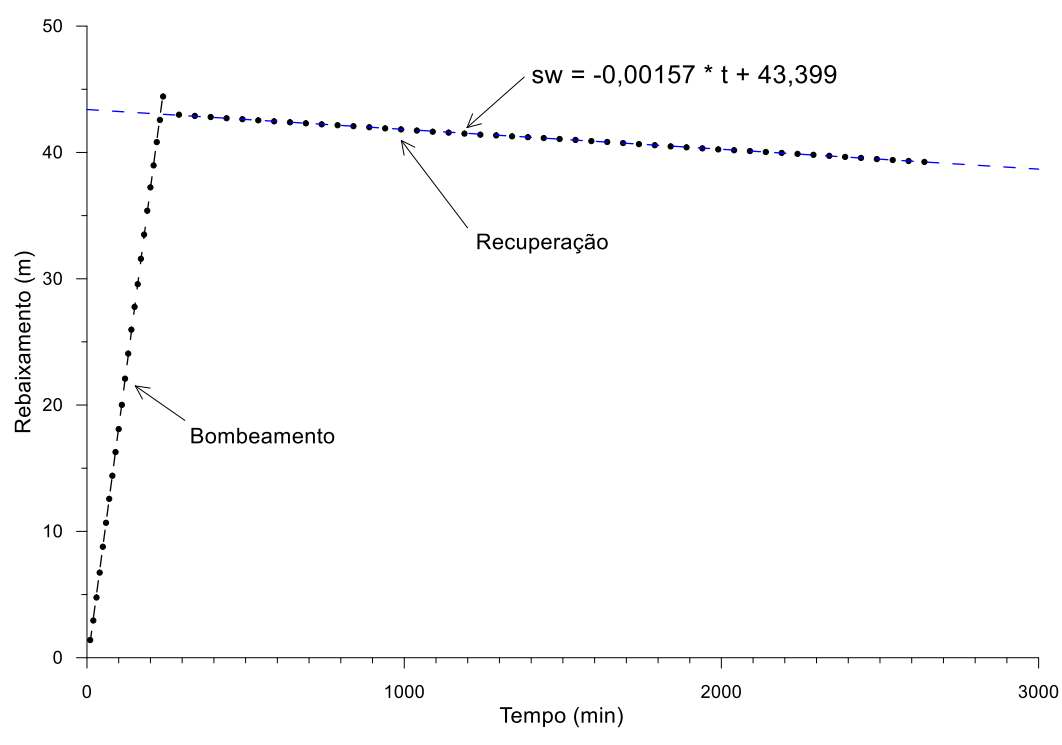

A curva de recuperação durante as quarenta horas, tal como a curva de bombeamento, ajusta-se perfeitamente a uma reta, o que mostra que processo de recuperação é semelhante ao do bombeamento, ou seja, enchimento a uma vazão constante de um reservatório cilíndrico, como já demonstrado.

Usando o mesmo raciocínio adotado para o bombeamento é possível determinar a vazão de "enchimento" do poço utilizando a equação de ajuste da recuperação:

$$
\begin{gathered}
s w=-0,00157 * \mathrm{t}+43,399 . \\
s w_{1 h}=-0,00157 * 60+43,399
\end{gathered}
$$

$$
\begin{gathered}
s w_{2 h}=-0,00157 * 120+43,399 \\
\Delta s w_{1 h}=s w_{2 h}-s w_{1 h} \\
\Delta s w_{1 h}=0,00157(120-60)=0,0942 m
\end{gathered}
$$

Ou seja, a cada hora o nível dinâmico sobe 0,0942m. Como o poço tem 10 polegadas isso corresponde a $0,0048 \mathrm{~m}^{3}$, ou aproximadamente 5,0 litros. Assim, a vazão de recuperação seria de aproximadamente 5,0 L/h.

Nenhum dos poços observados apresentou qualquer sinal de reação do nível da água durante as quarenta e quatro horas do teste. 
Pelos resultados dos pré-testes e do ensaio de bombeamento do $\mathrm{Pb}-03$ é possível admitir que todos os cinco poços têm vazões baixíssimas, praticamente secos. Diante desses resultados julgou-se que não seriam necessários a realização de ensaios de bombeamento semelhantes nos demais poços, as informações disponíveis já seriam conclusivas.

\section{4. "Slug" teste}

Como não se conseguiu obter nenhuma mensuração de parâmetro hidrogeológico do aquífero Jandaíra na área da Mizu, por meio de teste de aquífero convencional, se tentou um método alternativo, muito usado em estudos de meios porosos, o "slug" teste, que permite a determinação da condutividade hidráulica do aquífero.

O princípio do método baseia-se na retirada ou injeção de um determinado volume de água do poço instantaneamente. A principal dificuldade desse método é a condição da retirada ou injeção instantânea. Na prática, a forma mais usada é a introdução, ou retirada, de um cilindro no poço, denominado de slug. Para os testes foi utilizado um slug de PVC de um metro de comprimento e $75 \mathrm{~mm}$ de diâmetro, tamponado nas duas extremidades. 0 slug foi preenchido com brita para não flutuar.

A análise do Slug teste foi feita pelos métodos de Bouwer-Rice e Hvorslev. O método de Bower-Rice é utilizado para estimativa da condutividade hidráulica de aquíferos livres, utilizando um único poço, que pode ser parcial ou totalmente penetrante. 0 método Hvorslev é um dos mais usados para estimativa da condutividade hidráulica da zona dos filtros de um poço, e pode ser aplicado tanto para aquífero livre como confinado.

Na tabela 3 é apresentado um resumo dos valores de condutividades hidráulicas obtidas a partir dos slug testes.

É importante esclarecer que o Slug teste é uma metodologia para meio poroso, portanto, os valores de condutividade hidráulica encontrados seriam para um meio poroso equivalente.

Tabela 3 - Valores de condutividade hidráulica do aquífero Jandaíra

\begin{tabular}{ccc}
\hline Poço & \multicolumn{2}{c}{ Condutividade hidráulica $(\mathrm{m} / \mathrm{s})$} \\
& Bouwer-Rice & Hvorslev \\
\hline $\mathrm{Pb}-02$ & $1,17 \times 10^{-8}$ & $1,58 \times 10^{-8}$ \\
$\mathrm{~Pb}-03$ & $3,00 \times 10^{-8}$ & $3,20 \times 10^{-8}$ \\
$\mathrm{~Pb}-04$ & $1,63 \times 10^{-8}$ & $2,13 \times 10^{-8}$ \\
$\mathrm{~Pb}-05$ & $1,13 \times 10^{-7}$ & $1,43 \times 10^{-7}$ \\
Média & $4,28 \times 10^{-8}$ & $1,43 \times 10^{-8}$ \\
\hline
\end{tabular}

Os resultados obtidos no ensaio de bombeamento do poço $\mathrm{Pb}$ 03 e nos slug testes mostram que o aquífero Jandaíra na área da Mizu é de baixíssima produtividade. Porém, não se pode esquecer dois aspectos importantes para o problema aqui estudado: a) a natureza anisotrópica e heterogênea dos calcários e b) as condições climáticas do período estudado.

Com relação a natureza do aquífero cárstico, os meios fraturados são a essência da heterogeneidade e anisotropia, isto significa dizer que os resultados alcançados com os cinco poços de produção não podem ser estendidos indiscriminadamente para toda a área estudada.

Observa-se nas fazendas no entorno da Mizu poços de alta produtividade próximos a poços com características semelhantes aos poços de bombeamento aqui estudados.

Essas constatações vêm ao encontro das informações obtidas durante o levantamento geológico, que mostrou que as fraturas diminuem de abertura e quantidade com a profundidade, o que é compatível com a diminuição da produção dos poços com o aprofundamento dos níveis da água.

Assim, os resultados obtidos com o ensaio de bombeamento e slug teste têm que ser recebidos com cautela. As baixas vazões encontradas hoje podem ser uma mera consequência das condições climáticas atuais, ou seja, com o retorno das chuvas para normalidade, e a consequente recuperação dos níveis da água nos poços, é possível que os poços hoje improdutivos tornem-se produtivos novamente. A única maneira de testar essa hipótese de trabalho é executar novos testes quando as condições climáticas forem mais favoráveis.

\section{CONTRIBUIÇÃO PARA A ELABORAÇÃO DE UM MODELO CON- CEITUAL}

O modelo conceitual de um aquífero é uma representação pictórica de um sistema de fluxo de água subterrânea, frequentemente representado por um bloco diagrama ou por diagramas de cercas, ou secções (ANDERSON e WOESSNER, 1992, p.28).

O modelo conceitual é uma etapa preliminar e fundamental para a elaboração de um modelo numérico de fluxo subterrâneo, assim, apesar de simplificado, deve ser uma representação válida do aquífero a ser modelado, caso contrário pode-se chegar a resultados do modelo numérico totalmente dissociado da realidade.

Para se elaborar um modelo conceitual são necessárias as seguintes informações:

a) Geometria do aquífero, definida a partir dos mapas geológicos, perfis de poços e, quando disponível, levantamentos geofísicos. 
b) As condições de contorno definidas pela infiltração, relação do aquífero com rios, lagos, relação do limite do aquífero, ou da área modelada, com a parte externa.

c) A existência de poços de bombeamento ou injeção.

d) Parâmetros hidrogeológicos tais como transmissividade, condutividade hidráulica, coeficiente de armazenamento, porosidade efetiva.

e) Séries históricas de monitoramento embora sejam imprescindíveis na fase de calibração e validação do modelo, também ajudam na elaboração do modelo conceitual.

A principal característica hidrogeológica identificada do aquífero Jandaíra, ao longo do projeto, é a existência de dois horizontes de características hidrogeológicas bem distintas. 0 mais superior, que ocorre desde a superfície até aproximadamente vinte metros de profundidade, é mais carstificado, o que lhe confere uma boa capacidade de armazenamento de água. 0 mais inferior, a carstificação é menos intensa, consequentemente menor capacidade de acumulo de água. A profundidade de vinte metros como o limite entre as duas zonas é uma definição preliminar e, provavelmente, não deve ser algo regular, ou seja, essa profundidade deve variar de acordo com o local.

Já foi descrito nos itens anteriores que poços que antes eram produtivos, com o longo período de estiagem, hoje estão desinstalados sem produzir uma gota da água e as plantações, antes irrigadas, estão morrendo por falta de água.

Também foi descrito que dois poços próximos, ambos produtivos, com a estiagem um deles tornou-se improdutivo, enquanto o outro manteve a mesma produção.

Esses dois tipos de relatos são encontrados em vários locais no entorno da área de estudo. Essas situações, aliadas ao levantamento geológico, que demonstrou que as fraturas e a carstificação diminuem as aberturas com a profundidade, levou a elaboração da hipótese ilustrada na figura 6 , na qual são apresentados dois cenários, A) quanto o nível da água no aquífero Jandaíra está mais alto, nas épocas em que as chuvas são normais, e B) para as épocas de grandes estiagens, como a que se vem atravessando.

Figura 06- Hipótese de como se dar a carstificação do aquífero Jandaíra na área de estudo
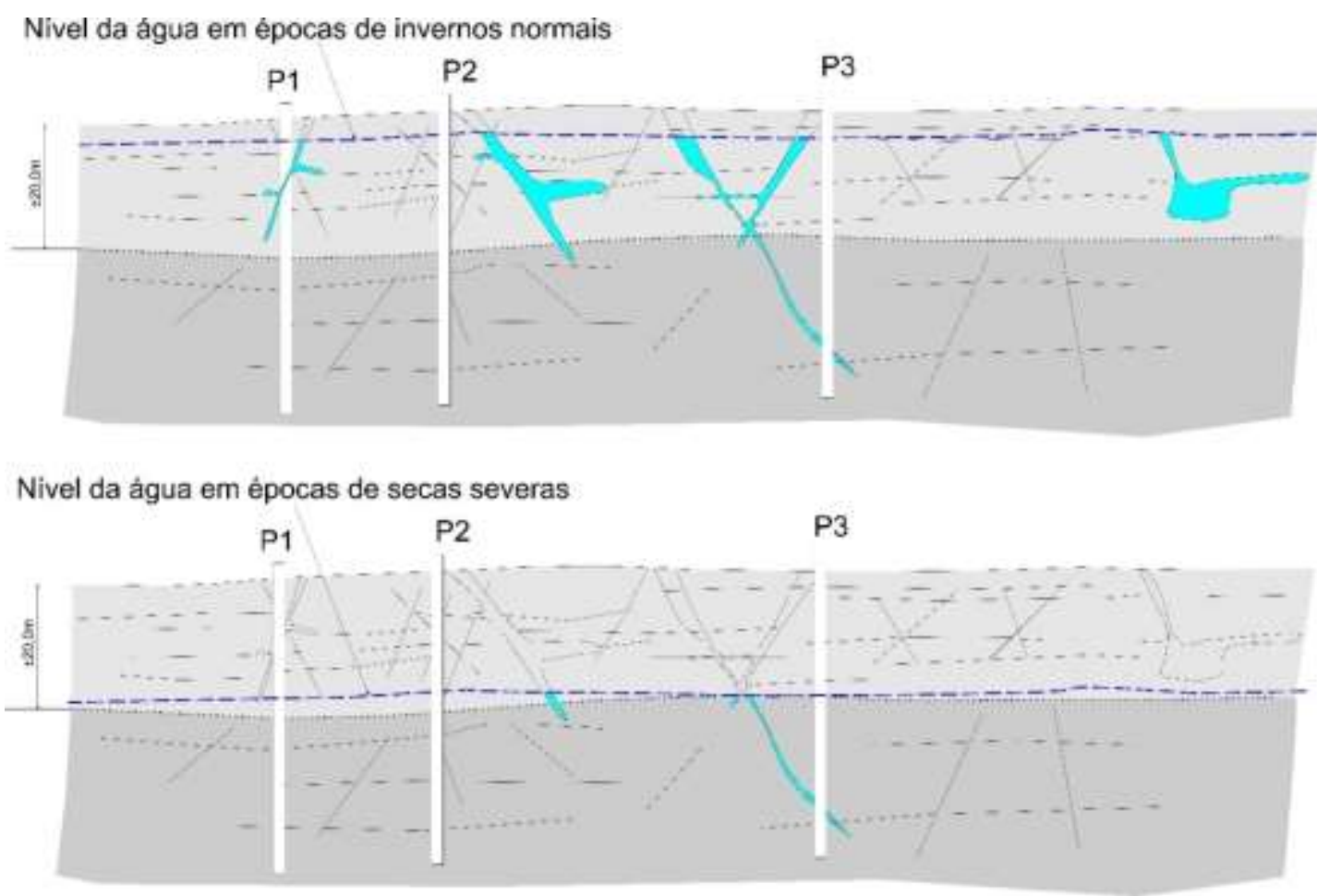

No cenário A, poços como o P1, na figura 6 , que captam um karst na parte superior têm sua produção de água equivalente aos poços que captam descontinuidades mais profundas, como o P3. Quando o nível da água baixa, nas épocas de grandes secas, só poço P3 continua produtivo. Mesmo poços como o P2, que não captam uma zona carstificada, apresentam uma produtividade razoável no período em que os níveis estão mais altos, tornandose seco quando os níveis baixam.

Essa concepção de comportamento hidráulico é sem dúvida uma contribuição importante para o conhecimento hidrogeológico do aquífero Jandaíra, pois, em nenhum trabalho pesquisado na lite- ratura essa diferenciação de zoneamento de carstificação foi mencionada. Assim, esse conhecimento permitirá um refinamento da concepção hidrogeológica do aquífero Jandaíra e na elaboração de trabalhos mais bem embasados e representativos.

\section{CONCLUSÕES}

$\mathrm{Na}$ área de trabalho o aquífero Jandaíra apresenta uma carstificação intensa até cerca de 20,0 metros de profundidade. Há uma diminuição da abertura das fraturas com a profundidade, ou seja, a carstificação diminui, o que era esperado, sugerindo 
que à medida que a água da chuva infiltrada se enriquece com carbonato, diminui o seu poder de dissolução. As fraturas até cerca de 20,0 metros de profundidade estão bem conectadas, fazendo com que a maioria dos poços apresentem boas vazões de produção. Quando a superfície freática fica abaixo dessa profundidade, só os poços que captam os sistemas de fraturas principais, as mais desenvolvidas, é que mantém a boa produtividade, os demais secam.

Hidraulicamente o aquífero Jandaíra comporta-se como se fosse dois aquíferos, um até cerca de 20,0 metros de profundidadee outro abaixo dessa profundidade.

A condutividade hidráulica equivalente, determinada por slug teste, são da ordem de $1 \times 10^{-8} \mathrm{~m} / \mathrm{s}$, demostrando que fora das zonas mais intensamente carstificadas os poços são improdutivos, comportando-se como verdadeiros cilindros fechados, com uma vazão de enchimento da ordem de 5,0 L/h.

\section{AGRADECIMENTOS}

Nossos agradecimentos a Cimento Mizu por ter nos dado a oportunidade de desenvolver esses estudos e permitir a sua publicação, em especial ao Líder Regional Dr. Antero dos Santos e ao geólogo Igor Gothardo.

Ao Sr. Assis pela presteza e paciência com que nos auxiliou nas atividades de campo.

\section{REFERÊNCIAS}

ANA-AGÊNCIA NACIONAL DE ÁGUAS. Avaliação dos recursos hídricos subterrâneos e proposição de modelo de gestão compartilhada para os aquíferos da chapada do Apodi, entre os Estados do Rio Grande do Norte e Ceará, Vol. II, Brasília, 2010.
ANDERSON, M.P; WOESSNER. Applied groundwater modeling: simulation of flow and adjective transport. 1.ed. San Diego: Academic press, 1992.

ANGELIM, L. A. A. Geologia e recursos minerais do estado do Rio Grande do Norte. Mapa geológico do Estado do Rio Grande do Norte, escala 1:500.000.Recife. CPRM-Serviço Geológico do Brasil, 2007.

ARARIPE, P. D. T., FEIJÓ, F. J. Bacia Potiguar. Boletim de Geociências da Petrobras, 8:127-141, 1994.

DEMÉTRIO, J. G. A., MELO, J. G., DINIZ FILHO, J. B., BATISTA, A. G. S. COSTA, O.R. Monitoramento do aquífero Jandaíra na região de BaraúnaRN. Águas Subterrâneas, 30: 261-268, 2016.

FEITOSA, E.C. O Problema do rebaixamento excessivo dos niveis de bombeamento do aquífero Jandaíra na região de Baraúna, extremo oeste da Bacia Potiguar: sugestão de abordagem. ANA/SIH, Natal. Relatório inédito, 2003.

FUNPEC/MIZU. Análise dos impactos do rebaixamento do nível das águas subterrâneas do aquífero Jandaíra na área da mina da "fábrica de cimento Mizu", situada no setor oeste da Bacia Potiguar/RN. Relatório técnico, inédito, 2013.

MANOEL FILHO, J.; DEMÉTRIO, J. G., COSTA, W. D. Possibilidades de am pliação da explotação de água subterrânea na zona oeste da Bacia Potiguar, RN: diagnóstico da situação atual. Fade-LABHID-UFPE/FUNCATE, Recife. Relatório, técnico, inédito, 2003.

MIRANDA, T. S., MANOEL FILHO, J., BRITO NEVES, B. B., BARBOSA, J. A., Estudo do comportamento geológico-estrutural dos depósitos cretácicos do sistema aquífero Apodi, Bacia Potiguar, NE do Brasil. Estudos Geológicos, 22:1-19, 2012. 